\title{
SYNTHESIS AND CHARACTERIZATION OF COPPER OXIDE DOPED WITH TITANIUM NANOPARTICLES
}

\author{
Usha Shukla ${ }^{1}$, Abhilasha Dhasmana ${ }^{2}$ \\ E-Mail Id: usha.shukla1@ gmail.com \\ ${ }^{1}$ Amity School of Applied Sciences, Amity University, Lucknow Campus, Uttar Pradesh, India \\ ${ }^{2}$ Manipal academy of higher education, Manipal. Karnataka, India
}

Abstract- Copper oxide ( $\mathrm{CuO})$ is a suitable material for the application of photovoltaic where the role of lattice defects is remarkable for shaping its other physical and optical properties. In the present study, we report the structural properties of Ti doped copper oxide (CuO: Ti) (with $\mathrm{x}=0,0.0078,0.0156,0.0234,0.0312$ ) nanostructures prepared by sol-gel method. The electrical property of $\mathrm{CuO}$ nanoparticles changes with changing the concentration of Ti dopant. The resistivity of undoped $\mathrm{CuO}$ is higher than the Ti doped $\mathrm{CuO}$. The $\mathrm{XRD}$ (X-ray diffraction) pattern results the formation of pure phase of $\mathrm{CuO}$ for $\mathrm{x}=0$ and no impurity phase is observed at $450^{\circ} \mathrm{C}$ and $600^{\circ} \mathrm{C}$.

Keywords: Copper oxide, $\mathrm{CuO}$ : Ti, sol-gel method, four point probe system and X-ray diffraction.

\section{INTRODUCTION}

Over the past years, the scientists and researchers have appeared their big interest own transition metal oxide because of their optical, magnetic, electrical properties, specific catalytic [1-4]. The shape, size, properties and the nature of particles has a huge effect in various fields such as in optoelectronic devices, sensors, drug design, batteries, solar cells, synthetic chemistry and catalysis. Facts of detection of crystal at nano-level will provide rigorous information about their wonderful properties which is different from their bulk.

In the modern time, extraordinary efforts were devoted towards the formation of transition metal oxide nanoparticle in accordance of physical and chemical properties. $\mathrm{CuO}$ is the excellent choice for the solar application because it uses entire visible spectrum due to its energy (direct or indirect) band gap of $1.2 \mathrm{eV}$. At the present time, doping in $\mathrm{CuO}$ has been significantly analyzed because the properties of $\mathrm{CuO}$ can be easily controlled by suitable dopant.

Due to photoconductive and photochemical properties of $\mathrm{CuO}$ p-type semiconductor, it is used in gas sensing, in catalysis, as antimicrobial agent, and in batteries, magnetic devices, super capacitors, and field emission [14]

Copper oxide has great attention in present years because of their potential application and special properties in the areas of technology [5-7]. CuO have the monoclinic structures. According to their impressive advantages as nontoxic nature, inexpensive, readily stored and easily produced [8]. CuO is used as catalyst among another metal oxide. $\mathrm{CuO}$ is also used to produce dry cell batteries.

There are vast ranges if synthetic method for the preparation of oxide likes sol-gel, sonochemical, solid state technique and hydrothermal methods [9-13]. We prepared the nanoparticles by sol-gel method. Sol-gel method is very strong and valid method controlling the size and shape of particles without requirement of any complex apparatus. The sol-gel is the prominent method to synthesis high purity advanced materials. Additionally, sol-gel is a low temperature process so it consumes less energy and creates less pollution.

Copper oxides doped with $\mathrm{Ti}$ are promising materials

for optoelectronics and may reduce production costs due to their low cost and inexpensive production methods compared with silicon solar cells which are potentially useful for inexpensive and competitive solar cell construction[15-16].

In the past few decades metal nanoparticles (silver and copper) and semiconductor nanoparticles have been used for the antifungal/antibacterial materials with the help of nanoscience and nanotechnology [17].

Doping of different transition metals vary their optical and structural properties in $\mathrm{CuO}$. Thus we report the effect on the structural properties of $\mathrm{CuO}$ due to doping by sol-gel method and four point probe system at different concentration of $\mathrm{Ti}$ ion.

\section{EXPERIMENTAL}

The materials used were copper oxide, nitric acid, ethylene glycol, citric acid and TALH (Titanium ammonium lactato dihydroxide) and double distilled water for the preparation of nanopowder.

Sol-gel method has synthesized the pure and $\mathrm{Ti}$ doped $\mathrm{CuO}$ at different doping concentration $(\mathrm{x}=0,0.0078,0.0156$, $0.0234,0.0312$ ). A precursor was produced by the liquefying copper in double distilled water under stirring and then was added drop wise with constant stirring. Then citric acid and ethylene glycol was added to give the gel. The gel was heated at room temperature for 3-4 hours and we get the powder form of $\mathrm{CuO}$. Powder were decarbonized and denitrified at $450^{\circ} \mathrm{C}$ and further annealed at $600^{\circ} \mathrm{C}$. 


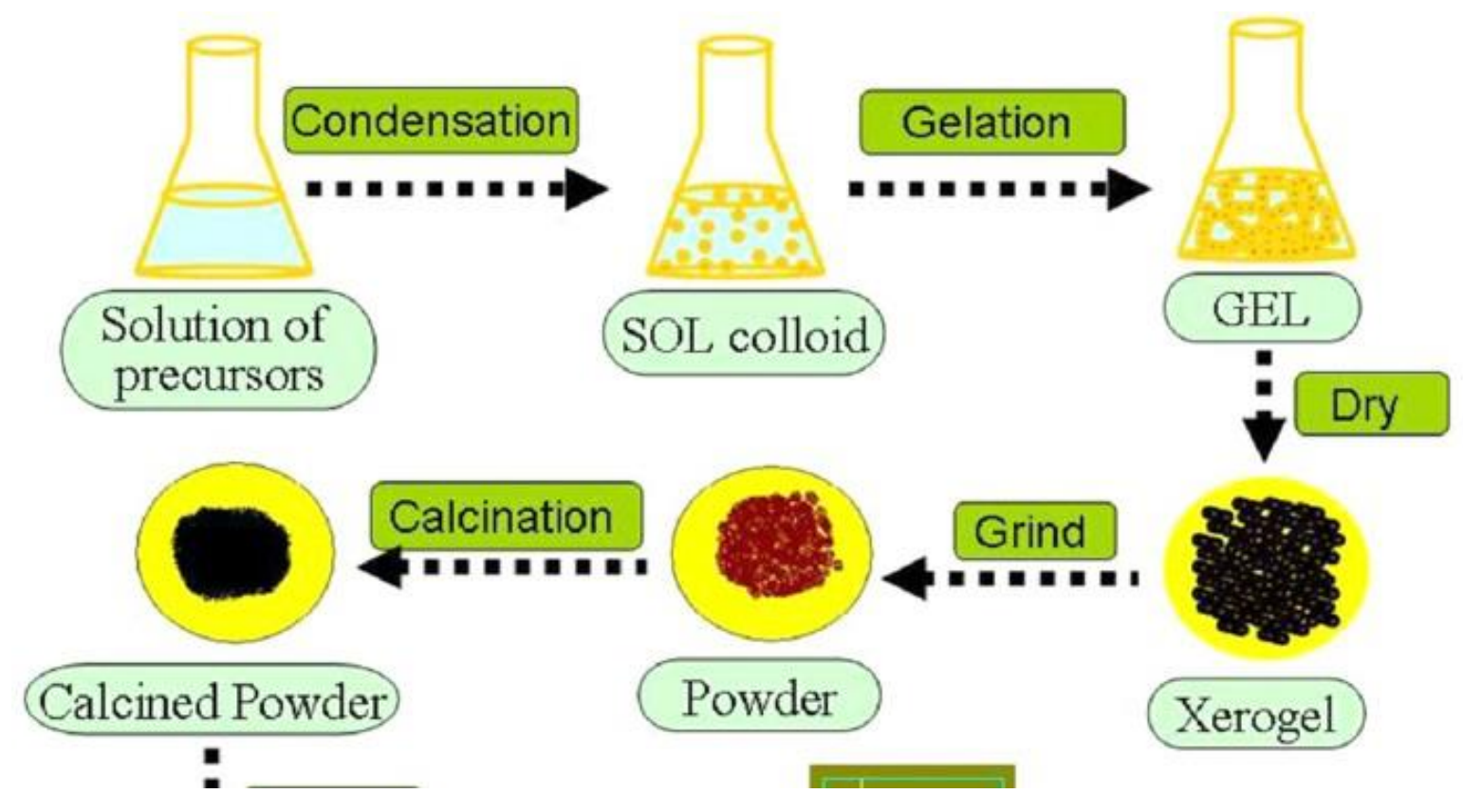

\section{CHARACTERIZATION TECHNIQUE}

\subsection{X-ray Diffraction}

When an X-ray is incident on a crystal, it diffracts the structure characteristic. The diffraction pattern is obtained by the powder of the material in powder X-ray diffraction. Powder diffraction is more convenient comparatively than single crystal diffraction because XRD does not require individual crystals to be made. A pattern obtained by the diffraction plots intensity against $2 \theta$, the angle of the detector.

A pattern obtained by the diffraction determines the purity of a sample. The composition of any present impurities can also be determined. Determination and refinement of the lattice parameters of a crystal structure can be done. The obtained samples were characterized for the analysis of structural and phase purity obtained with a step size 0.02 in the range of $2 \theta$ from 30 to $80^{\circ}$ with the help of X-ray diffractometer.

The glass substrate was used for the thin film deposition of $\mathrm{CuO}$ doped with $\mathrm{Ti}$ by using the four point probe system and measuring the resistivity of $\mathrm{CuO}$ with increasing the concentration of the $\mathrm{Ti}$ ion [16]. Table 1. Shows the sheet resistance of thin film of $\mathrm{CuO}$ : Ti nanoparticles with Ti concentration after annealed at $300{ }^{\circ} \mathrm{C}$.

Table-3.1 Sheet resistance of thin film of $\mathrm{CuO}$ : $\mathrm{Ti}$ nanoparticles with $\mathrm{Ti}$ concentrations after annealed at 300 ${ }^{\circ} \mathbf{C}[16]$

\begin{tabular}{|l|l|l|l|l|l|}
\hline & PURE CuO & X1 & X2 & X3 & X4 \\
\hline $\begin{array}{l}\text { Ti Sputtering } \\
\text { power (W) }\end{array}$ & 0 & 1 & 2 & 4 & 10 \\
\hline $\begin{array}{l}\text { Ti concentration } \\
(\%)\end{array}$ & 0 & 0.049 & 0.099 & 0.19 & 0.598 \\
\hline $\begin{array}{l}\text { Sheet resistance } \\
(\Omega / \text { square })\end{array}$ & $\sim 6 \times 108$ & $\sim 8 \times 106$ & $\sim 5 \times 106$ & $\sim 2 \times 106$ & $\sim 5 \times 105$ \\
\hline
\end{tabular}

\section{RESULT AND DISCUSSION}

Study of structure with the help of XRD release monoclinic single crystalline phase of $\mathrm{Cu}_{1-\mathrm{x}} \mathrm{Ti}_{\mathrm{x}} \mathrm{O}$ for all the synthesized samples with $(\mathrm{x}=0,0.0078 .0 .0234,0.0156$ and 0.0312$)$ at two different temperatures i.e. at $450^{\circ} \mathrm{C}$ for 6 hours and $600^{\circ} \mathrm{C}$ for 2 hours . All the samples are present in single phase. No peak of impurity phases is detected. This emphasizes that $\mathrm{Ti}$ is successfully incorporated in monoclinic structure of $\mathrm{CuO}$. Shifting of (111) diffraction peak to lower angles hints towards the increase in the lattice parameters. Further increasing the concentration of Ti dopant peak intensity decreases, this showing the dependence of crystal quality on Ti concentration. Indeed, in the lightly doped $\mathrm{CuO}$ : $\mathrm{Ti}$ nanoparticles, due to proper substitution of $\mathrm{Ti}$ in $\mathrm{CuO}$ lattice, no secondary defect phases are observed. However, in the highly doped $\mathrm{CuO}$ : Ti nanoparticles, the presence of more Ti-induced crystalline disordering resulted in lattice imperfection degrading the crystal quality of nanoparticles. 
ICAASET-2021, 20-21 May, 2021, K.R. Mangalam University, Gurugram

International Journal of Technical Research \& Science (Special Issue) ISSN No.:2454-2024 (online)

The effect of $\mathrm{Ti}$ concentration on the electrical conductivity of $\mathrm{CuO}$ : Ti thin films were investigated using a four point probe system. As shown in Table 1, the pure $\mathrm{CuO}$ exhibits a higher resistivity than the $\mathrm{Ti}$ doped $\mathrm{CuO}$. Higher incorporation of $\mathrm{Ti}$ decreased the resistivity of $\mathrm{CuO}$ : $\mathrm{Ti}$ nanoparticles continuously and the value were found to decrease by three orders of magnitude when the Ti concentration was $0.598 \%$. This significant reduction of resistivity of $\mathrm{CuO}$ : $\mathrm{Ti}$ can be explained on basis of charge compensation effect.

It was found that it is possible to improve the conductivity of the $\mathrm{CuO}$ : Ti nanoparticles by tuning the doping of $\mathrm{Ti}$.

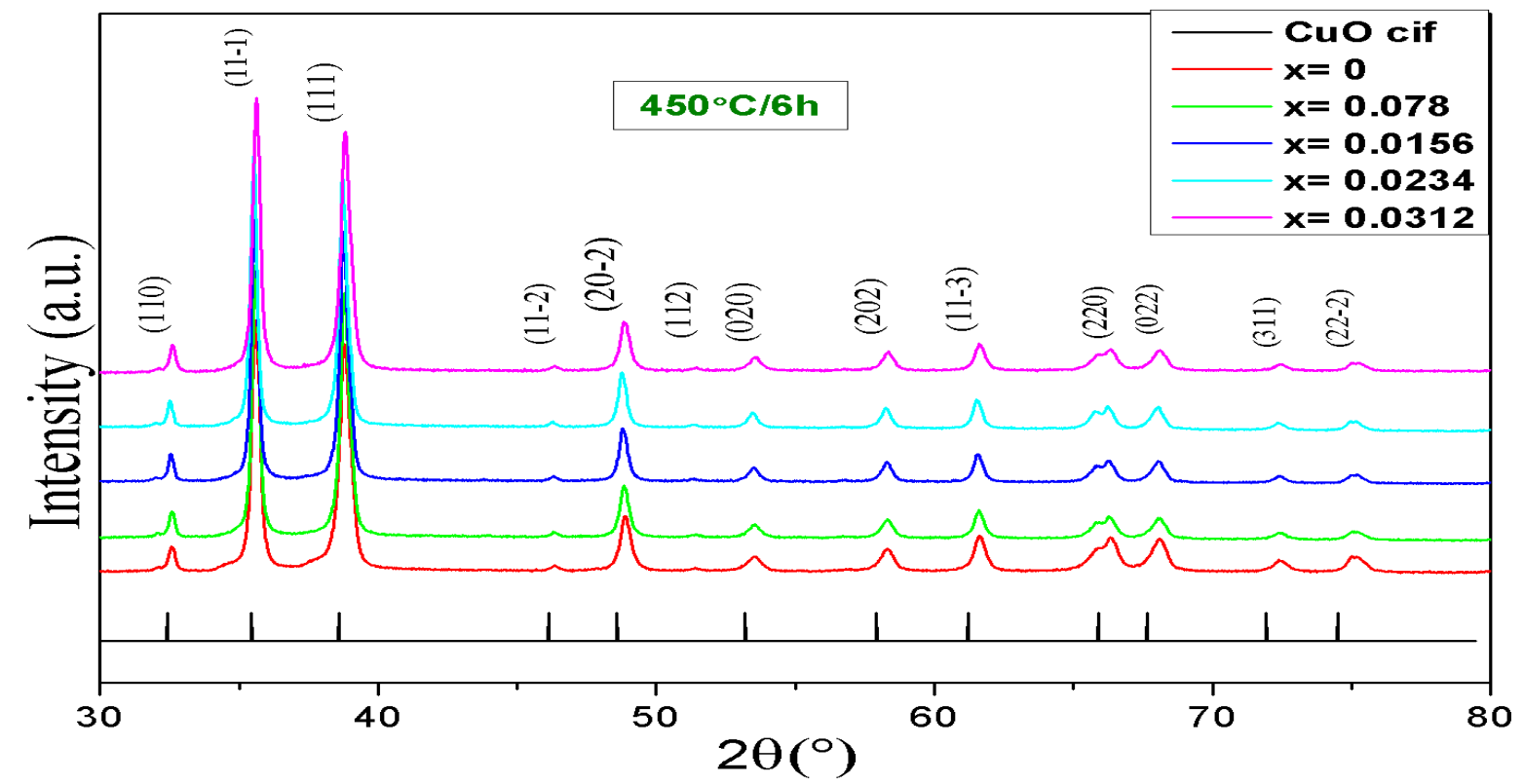

Fig. 4.1 X-ray diffraction pattern of $\mathrm{CuO}$ : Ti nanoparticles annealed at $450{ }^{\circ} \mathrm{C}$ for 6 hours

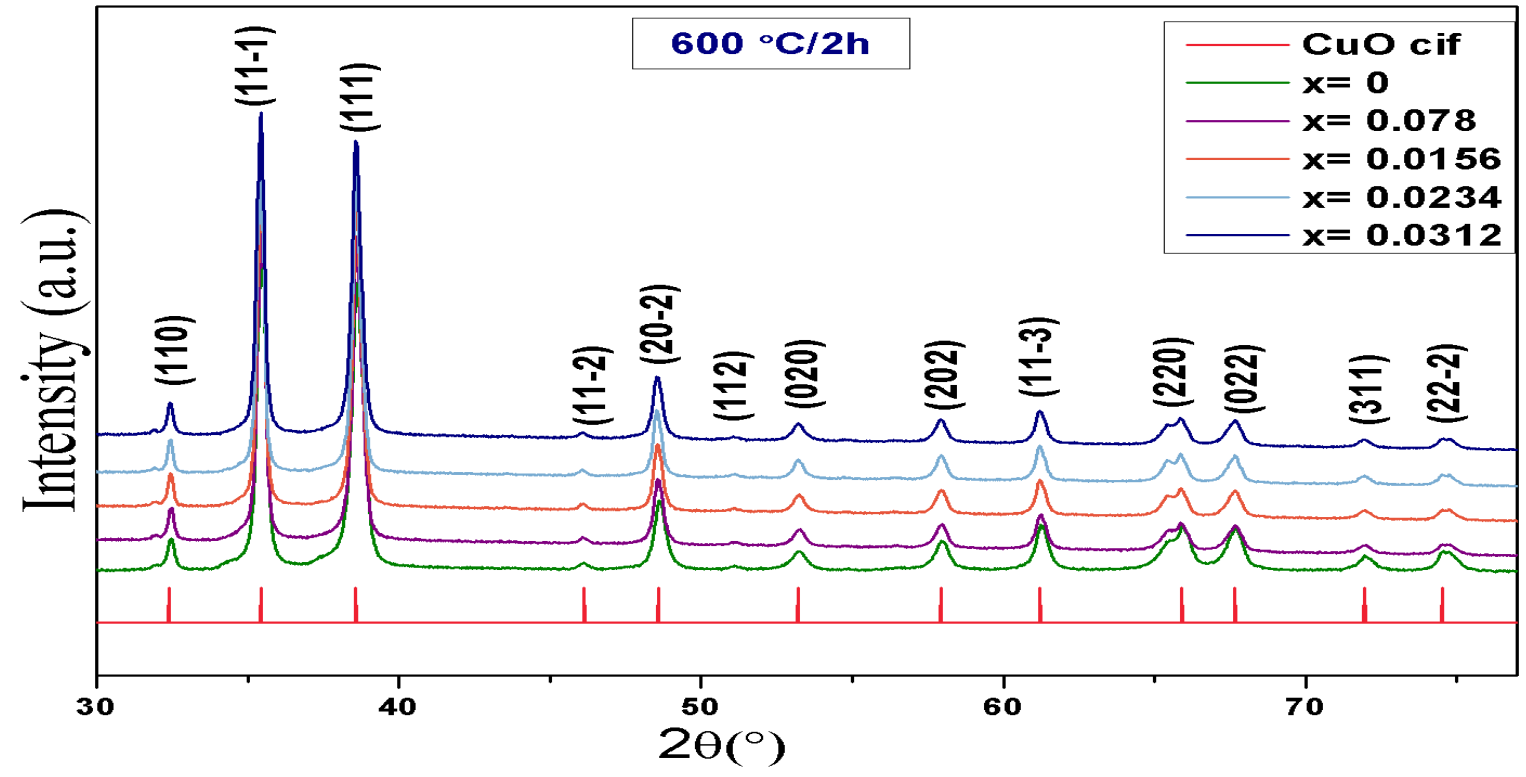

Fig. 4.2 X-ray diffraction pattern of $\mathrm{CuO}$ : Ti nanoparticles annealed at $600{ }^{\circ} \mathrm{C}$ for 2 hours

\section{CONCLUSION}

The structural properties of $\mathrm{Ti}$ ion substituted $\mathrm{CuO}$ nanoparticles with different doping concentration with $\mathrm{x}=0$, $0.0078,0.0156,0.0234,0.0312$ ) have been studied by sol-gel method. The pattern obtained by XRD tells about the pure phase of $\mathrm{CuO}$ and no impurity phase is observed in $\mathrm{Ti}$ doped $\mathrm{CuO}$ at $450^{\circ} \mathrm{C}$ and $600^{\circ} \mathrm{C}$. The effect of $\mathrm{Ti}$ concentrations on the resistivity of $\mathrm{CuO}$ has been studied by the four point probe system. It was found that the pure $\mathrm{CuO}$ exhibits a higher resistivity than that of $\mathrm{Ti}$ doped $\mathrm{CuO}$. Higher incorporation of $\mathrm{Ti}$ in Cuo lattice decreased the resistivity of $\mathrm{CuO}$ : Ti nanoparticles continuously. The present report provides a possible solution for the growth of Ti doped $\mathrm{CuO}$ for photovoltaic devices.

\section{REFERENCES}

[1] Zhang, Q. (eds): $\mathrm{CuO}$ nanostructures: Synthesis, characterization, growth mechanisms, fundamental properties, and applications. Progress in Materials Science 208 (2014) 60. 
ICAASET-2021, 20-21 May, 2021, K.R. Mangalam University, Gurugram

International Journal of Technical Research \& Science (Special Issue) ISSN No.:2454-2024 (online)

[2] Gaur, U.K. (eds): The synthesis of self-assembled polycrystalline 1-D CuO nanostructures in aqueous medium and a study of their multifunctional features. Cryst. Eng. Comm. 3005 (2014) 16.

[3] Chand, P. (eds): Structural, optical and ferroelectric behavior of $\mathrm{CuO}$ nanostructures synthesized at different $\mathrm{pH}$ values. Superlattices and Microstructures 129 (2013) 60.

[4] Zhou, K. (eds): Synthesis, characterization and catalytic properties of $\mathrm{CuO}$ nanocrystals with various shapes. Nanotechnology 3939 (2006) 17.

[5] Sahay, R. (eds): Synthesis and characterization of $\mathrm{CuO}$ nanofibers, and investigation for its suitability as blocking layer in $\mathrm{ZnO}$ NPs based dye sensitized solar cell and as photocatalyst in organic dye degradation. J. Solid State Chem. 261 (2012) 186.

[6] Gao, S. (eds): Green fabrication of hierarchical $\mathrm{CuO}$ hollow micro/nanostructures and enhanced performance as electrode materials for lithium-ion batteries. J. Phys. Chem. C. 19324 (2008) 112.

[7] Comanac, A.(eds): Optical conductivity and the correlation strength of high-temperature copper-oxide superconductors. Nat. Phys. 287 (2008) 4.

[8] Xiang, J.Y. (eds): Self-assembled synthesis of hierarchical nanostructured $\mathrm{CuO}$ with various morphologies and their application as anodes for lithium ion batteries. J. Power Sources 313 (2010) 195.

[9] Vijayakumar, R.(eds): Sonochemical preparation and characterization of nanocrystalline copper oxide embedded in poly(vinyl alcohol) and its effect on crystal growth of copper oxide. Langmuir 1406 (2001) 17.

[10] Zhang, Y. (eds): CuO shuttle-like nanocrystals synthesized by oriented attachment. J. Cryst. Growth 196 (2006) 291.

[11] Chand, P. (eds): Structural, optical and ferroelectric behavior of Cu1-xLixO $(0 \leq x \leq 0.09)$ nanostructures. Acta Metallurgica Sinica DOI 10.1007/s40195-014-0046-2, (2014).

[12] Wang, J. S. (eds): Synthesis of Copper Oxide Nanocrystals and the Growth Mechanism of Copper Oxide Nanorods. Mater and Design Mater. Des. 625 (2004) 25.

[13] Gartner, M. (eds): Spectroellipsometric characterization of sol- gel TiO2-CuO thin coatings. Thin Solid Films 417 (2004) $455-456$.

[14] Etape, E. Ngolui, L. (ede): Synthesis and Characterization of $\mathrm{CuO}, \mathrm{TiO} 2$, and $\mathrm{CuO}-\mathrm{TiO} 2$ Mixed Oxide by a Modified Oxalate Route.Journal of Applied Chemistry. 2017 (2017) 1-10.

[15] Ski, M. Rybak-Wilusz, E.(eds): Review of the development of copper oxides with titanium dioxide thin-film solar cells. AIP Advances 10 (2020) 1-11.

[16] 16.Masudy-Panah, S., Radhakrishnan, K. (eds): Titanium doped cupric oxide for photovoltaic application. Solar Energy Materials and Solar Cells 140 (2015) 266-274.

[17] 17. Pandiyarajan, T., Udayabhaskar, R.(eds): Synthesis and concentration dependent antibacterial activities of $\mathrm{CuO}$ nanoflakes. Materials Science and Engineering C. 33 (2013) 2020-2024. 